ORIGINAL ARTICLE

\title{
Urinary Iodine Level in Healthy Pregnant Women and its Correlation with Serum TSH \& FT4
}

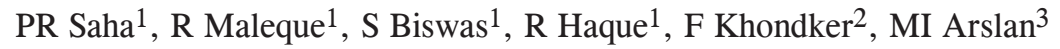 \\ ${ }^{1}$ Dept of Biochemistry, Sir Salimullah Medical College, Dhaka \\ ${ }^{2}$ Dept of Biochemistry, MARKS Medical college, Dhaka \\ ${ }^{3}$ Dept of Biochemistry, Bangabandhu Sheikh Mujib Medical University (BSMMU), Dhaka
}

\begin{abstract}
Pregnancy is accompanied by profound alteration of thyroid economy and relative iodine deficiency. Sub-optimal thyroid function in pregnancy is associated with impaired neuro intellectual development. Urinary iodine concentration is increased during pregnancy. The aims of this study were to evaluate urinary iodine level in pregnant women and also to elucidate its correlation with thyroid parameters (TSH\&FT4) in pregnancy. This was a case control study carried out in the Department of Biochemistry, jointly with the Antenatal and Thyroid Clinic of Bangabandhu Sheikh Mujib Medical University (BSMMU), Dhaka, during the period of July 2003 to June 2004. Urinary iodine excretion was measured in 100 subjects of age range 20-35 years. Among them 60 were pregnant at first trimester and primi gravid. Rest 40 were non-pregnant women who were taken as control. Urinary iodine was measured by Wet digestion based on Sandell-Kolthoff principle. Thyroid Stimulating hormone (TSH) and free thyroxin (FT4) were measured by the AxSYM (Abbott -USA) by applying Micro particle Enzyme Immune Assay (MEIA) principle. The data was reported as Mean \pm SE; the mean age of the pregnant and nonpregnant women were $25.03 \pm 0.48$ yrs and $25.20 \pm 0.60 \mathrm{yrs}$ respectively. No significant difference was found regarding age. The median urinary iodine of pregnant women was $438.13 \mu \mathrm{g} / \mathrm{l}$ (range240.50-490.0) and that non pregnant women was $412.50 \mu \mathrm{g} / \mathrm{l}$ (range $240.0-473.75 \mu \mathrm{gl}$ ). Mean serum TSH were $1.29 \pm 0.15$ and $1.97 \pm 0.18 \mathrm{mIU} / \mathrm{L}$ and mean serum FT4 were $14.51 \pm 0.41$ and 16.30 $\pm 0.41 \mathrm{pmol} / \mathrm{L}$ in pregnant and non pregnant women respectively. Urinary iodine level was significantly increased in pregnant women compared to that of the non pregnant group $(\mathrm{p}<0.05)$. A significant negative correlation was found between urinary iodine and serum TSH $(p<0.01)$ whereas a positive correlation between urinary iodine and serum FT4 level is $\mathrm{p}<0.05$ in pregnant and $\mathrm{p}<0.01$ in non pregnant group. Urinary iodine excretion is increased in pregnancy than that in non pregnant women. Clinically and biochemically all the subjects were euthyroid and excretion rate of iodine in all subjects were above the normal range.
\end{abstract}

Key Words : Iodine, thyroid, pregnancy

\section{Introduction}

Iodine is the trace element required by the body in optimum amount for the synthesis of thyroid hormone in human beings. Thyroid hormone plays a major role in the development of different functional components in different stages of life. Normally in fetal life it helps in

organogenesis. Iodine deficiency at critical stage during pregnancy and early childhood results in impaired development of the brain and consequently impaired mental function. People living in the iodine deficiency area may have an intelligence quotient (IQ) of up to 13.5 points

Bangladesh J Med Biochem 2015; 8(1): 21-26 
Urinary Iodine Level in Healthy Pregnant Women and its Correlatin below that of those communities without iodine deficiency ${ }^{20}$. Pregnancy is accompanied by profound alteration of thyroid economy and relative iodine deficiency ${ }^{2}$. Hormonal changes and metabolic demands during pregnancy result in profound alteration in the biochemical parameters of the thyroid function. The steadystate equilibrium of the physiological thyroid hormones are markedly modified during pregnancy because of high circulating levels of human chorionic gonadotropin (hCG) with its thyrotrophic action by a reciprocal fall in TSH that persists till middle of pregnancy. The increase in serum thyroxine-binding globulin as a consequence of high estrogen levels is accompanied by a trend toward a reduction of free thyroxine (FT4) and tri-iodothyronine (FT3) concentration with intense iodothyronine deiodination activity of the placenta ${ }^{4}$. It strongly suggests that early maternal hypothyroxiemia (i.e. low circulating free thyroxine before onset of fetal thyroid function at mid gestation (18-20 weeks) increases the risk of neurodevelopmental deficit of the fetus, despite the mother is not clinically hypothyroid ${ }^{1}$. Suboptimal thyroid function in pregnancy is associated with impaired neuro-intellectual development in several studies $19 \%$ with I.Q. $<85$ compared to $5 \%$ of another one study ${ }^{14}$. In pregnancy, the renal clearance of iodine increases significantly because of an increased glomerular filtration rate (GFR). Renal hyper filtration and increased clearance of iodine begin in the early weeks of gestation and persist until term, thereby constituting an obligatory renal iodine 'leakage ${ }^{8}$. Even in moderate iodine deficient region urinary iodine excretion is high in all trimester than in nonpregnant women. This could be a causative factor in maternal goiter formation, as assessed by ultrasound ${ }^{14}$.

The median urinary iodine excretion of $145 \mu \mathrm{g} / \mathrm{L}$ for the United States is nearly optimal in pregnant women. It implies an iodine intake of about $200 \mu \mathrm{g} / \mathrm{d}$. This value is comfortably above the recommended minimum ${ }^{9}$ level of $120 \mu \mathrm{g} / \mathrm{l}$ and also was the best cut-off value for low iodine excretion to identify endemic goiter in pregnant women ${ }^{7}$. The commonly used cutoff point of is $100 \mu \mathrm{g} / 1$. This value may underestimate the prevalence of iodine deficiency disorders during pregnancy. There was no independent effect of body weight and age on thyroid volume. Increased thyroid volume is observed in relation to parity. There is a cumulative goitrogenic effect of successive pregnancies. This provides a strong argument to indicate the need to increase the iodine supply to pregnant women to an adequate level of $200 \mu \mathrm{g} / \mathrm{day}$ as recommended by WHO. The nutritional needs for iodine is increased during pregnancy, mostly in first trimester. This provides a 25 to $50 \%$ increase of maternal T4 production in euthyroid women. At this stage T4 is needed for the development of embryo, fetal brain and to compensate for increased renal loss ${ }^{5}$. Bangladesh is an endemic area of iodine deficiency although large scale universal salt iodization has been adopted for the alleviation of IDD since 1989. Because it is essential to maintain the adequate iodine level in pregnant women, any alteration of maternal thyroid function results in a decreased availability of thyroid hormone to the fetal brain. This is potentially adverse for neuron development of fetus. So, concern about impaired intelligence and psychomotor development had lead the suggestion that women should be screened for hypothyroidism by estimation of urinary iodine.

\section{Material and Methods}

This case control study was carried out from July 2003 to June 2004 in the Department of Biochemistry, jointly with the Antenatal and Thyroid Clinic of Bangabandhu Sheikh Mujib Medical university (BSMMU), Dhaka. Permission for the study was taken from the concerned departments, authorities. and all participants gave written informed consent for the study. One hundred subjects were included. Out of them sixty were pregnant women and forty were nonpregnant women. Many pregnant women were in the Ist trimester and few were primi gravida. Age of all subjects was between $20-35$ years. They 
were apparently healthy and clinically euthyroid. Pregnant women of Ist trimester and primi gravid were diagnosed by history of amenorhorea, The Pregnancy test was urinary hCG and they were confirmed by ultrasonography. Non- pregnant women were excluded by the history. The gestational age was confirmed by Ultraso nography \& date of last menstruation period (L.M.P.). Clinically euthyroid cases were diagnosed by no palpable or visible neck swelling, no change of voice, no history of heat or cold intolerance. Any other diseases like diabetes mellitus, ischemic heart disease, liver diseases and /or renal diseases, subjects taking the drugs, which can influence the thyroid hormone concentration were excluded. Base line demographic data were collected. Blood samples were collected and were centrifuged at $2500 \mathrm{rpm}$ after clot have been formed and retracted for estimation of serum TSH \& Free thyroxine (FT4). Random urine samples were collected in a dry, clean and fresh glass container free from any chemical contamination for the estimation of urinary iodine. The urinary iodine was estimated by Spectrophotometer after digestion with acid in heating block (Fisher scientific company) ${ }^{20}$.

Thyroid Stimulating hormone (TSH) and free thyroxine (FT4) were measured by ASYM (Abbott -USA) by applying Micro particle Enzyme Immune Assay (MEIA) principle. The values were presented Mean \pm SE. Student's't' test \& Pearson's correlation coefficient test ('r'test) were done to see the level of significance and correlation between different parameters respectively. The significant test was done at $95 \%$ confidence level. $\mathrm{P}$ value of $<0.05$ was considered as level of significance. The level of significance for median values of urinary iodine concentration was done by Mann-Whitney U test.

\section{Result}

A total of 100 subjects were selected. They were divided in two groups. Those who are non-pregnant as Group-I and who are pregnant (1st trimester Prime gravida) as Group-II. Samples were collected during gestational period ranging from 812 weeks. Results are expressed as Mean \pm SE.
Age and body weight distribution of the groups are depicted in table I. Groups were similar in terms of age and body weight with no statistical difference, $p>0.05$ Table II shows Urinary iodine concentration and serum TSH \& FT4 of the subjects. Mann-Whitney $U$ test was done, as urinary iodine concentration does not follow normal distribution (Gaussian distribution). Urinary iodine concentration was significantly increased in pregnancy in comparison to nonpregnant control group $(\mathrm{p}<0.05)$. TSH and FT4 was significantly reduced in pregnant women than those in the control group $(\mathrm{p}<0.01)$. There was a significant negative correlation of urinary iodine with serum TSH level in both groups and a significant positive correlation was found between urinary iodine and serum FT4 in both groups. Regarding percentage of population distributed, it was seen that urinary iodine (UI) level was $401-450 \mu \mathrm{g} / \mathrm{l}$ and $451-500 \mu \mathrm{g} / \mathrm{l}$ in $35 \%$ and $36.6 \%$ of population respectively in pregnancy. $401-450 \mu \mathrm{g} / \mathrm{l}$ and $451-500 \mu \mathrm{g} / \mathrm{l}$ in $40 \%$ and $12.5 \%$ of population in control group. None of them had UI level $<200 \mu \mathrm{g} / \mathrm{L}(\mathrm{Tab}$ V \& VI)

Table I: Age \& body weight of subjects.

\begin{tabular}{|c|c|c|c|}
\hline \multicolumn{4}{|c|}{$\begin{array}{l}\text { Parameters -- non pregnant women - pregnant women } p \text {-value } \\
\qquad n=40\end{array}$} \\
\hline \multicolumn{3}{|l|}{ mean $\pm \mathrm{SE}$} & $\mathrm{p}>0.05$ \\
\hline \multicolumn{4}{|c|}{ Weight (kg) } \\
\hline mean $\pm \mathrm{SE}$ & $51.98 \pm 0.77$ & $51.88 \pm 0.63$ & $\mathrm{p}>0.05$ \\
\hline
\end{tabular}

Table II: urinary iodine concentration and Serum TSH \& FT4 levels of subjects.

\begin{tabular}{lccc}
\hline Parameters - & $\begin{array}{c}\text {-non pregnant } \\
\text { women } \\
(\mathbf{n}=\mathbf{4 0})\end{array}$ & $\begin{array}{c}\text { pregnant } \\
\text { women } \\
(\mathbf{n}=\mathbf{6 0})\end{array}$ & p value \\
\hline Median UI & 412.50 & 438.13 & $\mathrm{p}>0.05$ \\
level $(\mu \mathrm{g} / \mathrm{L})$ & $(240.00-473.75)$ & $(240.50-490.00)$ & \\
$\mathrm{TSH} \mathrm{mIU} / \mathrm{L}$ & $1.97 \pm 0.18$ & $1.29 \pm 0.15$ & $\mathrm{p}<0.01$ \\
$(\mathrm{mean} \pm \mathrm{SE}$ & & & \\
$\mathrm{FT}_{4} \mathrm{pmol} / \mathrm{L}$ & $16.30 \pm 0.419$ & $1.29 \pm 0.15$ & $\mathrm{p}<0.01$ \\
$(\mathrm{mean} \pm \mathrm{SE})$ & & & \\
\hline
\end{tabular}


Tab III: Correlation between urinary iodine (UI) concentration. \& TSH of two groups.

\begin{tabular}{lcccc}
\hline $\begin{array}{c}\text { Group Median UI } \\
\mu \mathrm{g} / \mathrm{L}\end{array}$ & $\begin{array}{c}\mathrm{TSH} \\
\mathrm{mIU} / \mathrm{L} \\
\text { (mean } \pm \mathrm{SE})\end{array}$ & $\begin{array}{c}\text { correlation } \\
\text { coefficient } \\
\text { 'r' value }\end{array}$ & 'p'value \\
\hline Gr-I & & & & \\
$(\mathrm{n}=40)$ & $412 . .50$ & $1.97 \pm 0.18$ & -0.791 & $\mathrm{p}<0.01$ \\
$\begin{array}{l}\text { Gr-II } \\
(\mathrm{n}=60)\end{array}$ & 438.13 & $1.29 \pm 0.15$ & -0.90 & $\mathrm{p}<0.01$ \\
\hline
\end{tabular}

Tab IV: Correlation between urinary iodine (UI) concentration. \& FT4 of two groups.

\begin{tabular}{lllll}
\hline Group Median UI & $\begin{array}{c}\text { FT } 4 \\
\text { pmol/L } / \mathrm{L} \\
\mu \mathrm{g} / \mathrm{L}\end{array}$ & $\begin{array}{c}\text { correlation } \\
\text { coefficient }\end{array}$ & 'P'value \\
(mean \pm SE) & r' value & \\
\hline $\begin{array}{l}\text { Gr-I } \\
(\mathrm{n}=40)\end{array}$ & $412 . .50$ & $16.30 \pm 0.41$ & 0.315 & $\mathrm{p}<0.01$ \\
$\begin{array}{l}\text { Gr-II } \\
(\mathrm{n}=60)\end{array}$ & 438.13 & $14.51 \pm 0.41$ & 0.452 & $\mathrm{p}<0.01$ \\
\hline
\end{tabular}

Table V: Frequency and percentage of pregnant women distributed according to urinary iodine level

\begin{tabular}{lll}
\hline $\begin{array}{l}\text { U I level } \\
\mu \mathrm{g} / \mathrm{L}\end{array}$ & Frequency & Percent (\%) \\
\hline$<200$ & 0 & 0 \\
$201-250$ & 1 & 1.7 \\
$251-300$ & 0 & 0 \\
$301-350$ & 4 & 6.66 \\
$351-400$ & 12 & 20 \\
$401-450$ & 21 & 35 \\
$451-500$ & 22 & 36.66 \\
Total & 60 & 100 \\
\hline
\end{tabular}

TableVI: Frequency and percentage of Non- pregnant women distributed according to UI level.

\begin{tabular}{llc}
\hline $\begin{array}{l}\text { U I level } \\
\mu \mathrm{g} / \mathrm{L}\end{array}$ & Frequency & Percent (\%) \\
\hline$<200$ & 0 & 0 \\
$201-250$ & 2 & 5 \\
$251-300$ & 1 & 2.5 \\
$301-350$ & 2 & 5 \\
$351-400$ & 14 & 35 \\
$401-450$ & 16 & 40 \\
$451-500$ & 5 & 12.5 \\
Total & 40 & 100 \\
\hline
\end{tabular}

\section{Discussion}

The effect of pregnancy on maternal thyroid economy and also on fetus have been widely studied $^{5}$. As the majority of ingested iodine is excreted in the urine, the measurement of urinary iodine excretion provides an accurate approximation of dietary iodine intake ${ }^{20}$. Maternal iodine deficiency leading to fetal hypothyroidism results in cretinism characterized by severe mental retardation ${ }^{10}$. The aim of the present study was to find out body iodine status, serum TSH and FT4 level and the correlation of urinary iodine level with thyroid parameters during pregnancy.

This study revealed that the median urinary iodine level was highly increased above the recommended normal level in both groups and significantly increased in pregnancy than that innonpregnant women. Serum TSH \& FT4 concentration were decreased significantly in pregnancy in comparison to the control group. There is increased renal loss of iodine in pregnancy and it was also noted in the present study that maternal urinary iodine excretion is increased in gestation. This is due to increased GFR (glomerular filtration rate) and increased renal clearance of iodine during pregnancy ${ }^{13}$.

Different studies also showed that the urinary iodine level was significantly increased in pregnant women than that in non-pregnant women ${ }^{2,17}$.

In this study, it was observed that mean serum FT4 level was significantly decreased in pregnant women than that in control group but remains within normal range. This is probably due to rise of total $\mathrm{T} 4$ resulting from the increase in thyroxine binding globulin (TBG) levels under the influence of elevated estrogen concentration in first trimester. However, these changes are very small so that in most pregnant women serum free $\mathrm{T} 4$ concentration remains within the normal range as in non-pregnant women.The findings of our study were consistent with the observations reported by different groups. Studies in iodine deficiency areas like Sudan had similar findings like ours 
but studies in Sweden which is not iodine deficient contradict our results $5,12,11$. It was demonstrated that there was progressive decrease of serum FT4 level in deficient areas, whereas, FT4 level remains within normal limit in iodine sufficient area. The mean serum TSH concentration was significantly reduced in pregnancy. The finding of our study is consistent with the observations reported by others ${ }^{13}$.

The low serum TSH level during first trimester is probably due to production of hCG which begins during the first week after fertilization and has highest level near the end of the first trimester. A high hCG level in first trimester leads to hCG cross reactivity with the TSH receptor, which inturn decreases serum thyrotropin concentration during first trimester ${ }^{5}$. Someone reported that, there was no significant difference in serum TSH and FT4 level in pregnancy when compared to that in the control group, both of them decreased in pregnancy than that in non-pregnant women and remains within normal limit ${ }^{3}$. In our study, we observed a significant decrease of TSH and FT4 level in pregnancy as compared to non-pregnant control ( $\mathrm{p}$ $<0.01$ ) but in both cases the levels were within normal range. This difference is probably due to fluctuation of TSH and FT4 level, depends on the estrogen and hCG which varies from person to person $^{15}$.

There was a significant negative correlation between urinary iodine and serum TSH level and a positive correlation between urinary iodine and serum FT4 level in both the groups. This correlation was similar to that noted by others ${ }^{6}$.

Regarding the percentage of population distribution according to the urinary iodine level, the urinary iodine concentration lies in between $451-500 \mu \mathrm{g} / \mathrm{L}$ in $36.6 \%$ in pregnant population whereas it is only $12.5 \%$ in non-pregnant control group. None of the subjects had a urinary level $<200 \mu \mathrm{g} / \mathrm{L}$, most of the population in both the groups had urinary iodine level above $350 \mu \mathrm{g} / \mathrm{L}$. About $10 \%$ of the study group had urinary iodine excretion within normal range $(100-300 \mu \mathrm{g} / \mathrm{L})$ and $90 \%$ had above normal range.

In this study there was a significant difference of thyroid parameters (TSH, FT4) between pregnant and non-pregnant women. Urinary iodine level was highly increased in both the groups and it was significantly increased in pregnancy. On the basis of the above description, it can be assumed that pregnancy has an important influence on thyroid function and urinary iodine level. So, pregnant women need to be screened for iodine deficiency by estimation of urinary iodine, as it is not influenced by hCG \& estrogen levels. This awareness will subsequently help to give adequate attention to iodine deficiency in an attempt to reduce the risk of neuro-developmental defect of the fetus.

\section{Reference}

1. Autric RL, Auso E, Velasco JVG, Arufe MC, Escobar del R, Berbel $\mathrm{P}$ et al. 'Early maternal hypothyroxinemia alters histogenesis and cerebral cortex cytoarchitecture of the progeny'. J ClinInvest 2003; 111(7): 1073-1082

2. Azizi F, Aminorroya A, Hedayati M, Rezvanian H, Amini M \& Mirmiran P. 'Urinary iodine excretion of pregnant women residing in areas with adequate iodine intake'. Public Health Nutr 2003;6(1) : 95-8.

3. Begum K. 'Study of Thyroid Hormone status in early normal pregnancy', M.D thesis, Bangabandhu Sheikh Mujib Medical University, Dhaka. 2002.

4. Burrow GN .'Thyroid status in normal pregnancy $\mathbf{J}$ clin Endocrinol Metabol 1990;71: 274 -275.

5. Burrow G N, Fisher D A \& Larsen P R. ' Maternal and fetal thyroid function'. N Eng J Med 1994;331: 1072-1078.

6. Caron P, Hoff M, Bazzi S, Durof A, Faure G, Ghandour I. et al. Urinary iodine excretion during normal pregnancy in healthy women living in the south west of France: Correlation with maternal thyroid parameters'. Thyroid 1997;7(5): 749-54.

7. Castaneda R, Lechuga D, Ramos R I, Magos C, Orozco M \& Martinez H. Endemic goiter in pregnant women: Utility of the simplified classification of thyroid size by palpation and urinary iodine as screening tests'. B J O G 2002; 109(12) : 1366-72. 
8. Dafnis E \& Sabatini S. 'The effect of pregnancy on renal function: physiology Pathophysiology'. Ame J Med Sci 1994; 303: 184-205

9. Dunn JT. 'What's Happening to our Iodine' The J of Clin Endocrinol \& Metabol 1998;43(10): 3398 -3400 .

10. Dunn JT \& Delange F. Damaged Reproduction: The Most Important Consequence of Iodine Deficiency. J of Clin Endocrinol \& Metabol 2001;86(6): 2360 -2363.

11. Elanger B, Elton A, Wide L, Cebre-Methin M. \& Karlsoon PA. Iodine status, thyroid function and pregnancy: study on Swedish and Sudanese women'. Eur J clin Nutr 1998; 52: 351-355.

12. Glinoer D, de Nayer P \& Bourdoux P. 'Regulation of maternal thyroid during pregnancy'. J Clin. Endocrinol Metab 1990;71 : 276-287.

13. Glinoer D. 'Pregnancy and Iodine'. Thyroid 2001;11(5) : 471-81.

14. Lararus JH. 'Epidemiology and prevention of thyroid disease'. Thyroid 2002;12 (10): 861-65.

15. Pakonen F, Alfthan H, Stenman UH \& Ylikorkala O. 'Human chorionic gonadotropin (hCG) and Thyroid function in early pregnancy; circadian variation and evidence for intrinsic thyrotropic activity for hCG. J clin Endocrinol Metabol $1988 ; 66: 853-856$.
16. Rotondi M, Amato G, Biondi B, Andrea del Buono G M, Nicchio M R, Balzano S. et al. 'Parity as a thyroid Size-Determining Factor in Areas with Moderate Iodine Deficiency'. J Clinical Endocrinol \& Metabol 2003;85(12): 4534 -4537.

17. Shi L, Tian Y, Piao J \& Xu J. 'Iodine nutritional status of pregnant, lactating women and children in Linxia Region of Gansu province'. Wei Sheng Yan Jiu 2002;31(4) : 282-4.

18. Smallridge RC \& Ladenson PW . 'Hypothyroidism in Pregnancy: Consequences to Neonatal Health Maternal and fetal thyroid physiology. J Clinical Endocrinol \& Metabol 2001;86(6): 2349- 2353.

19. Smyth PPA, Hetherton AMT, Smith DF, Radeliff M \& Herlihy CO. ' Maternal Iodine Status and Thyroid Volume during Pregnancy: Correlation with Neonatal Iodine Intake', J of Clinical Endocrinol \& Metabol 1997;82(9): 2840-2843.

20. WHO 2001, 'Assessment of deficiency disorders and monitoring their elimination'.A guide for programme managers. 2nd ed. Geneva: WHO. 